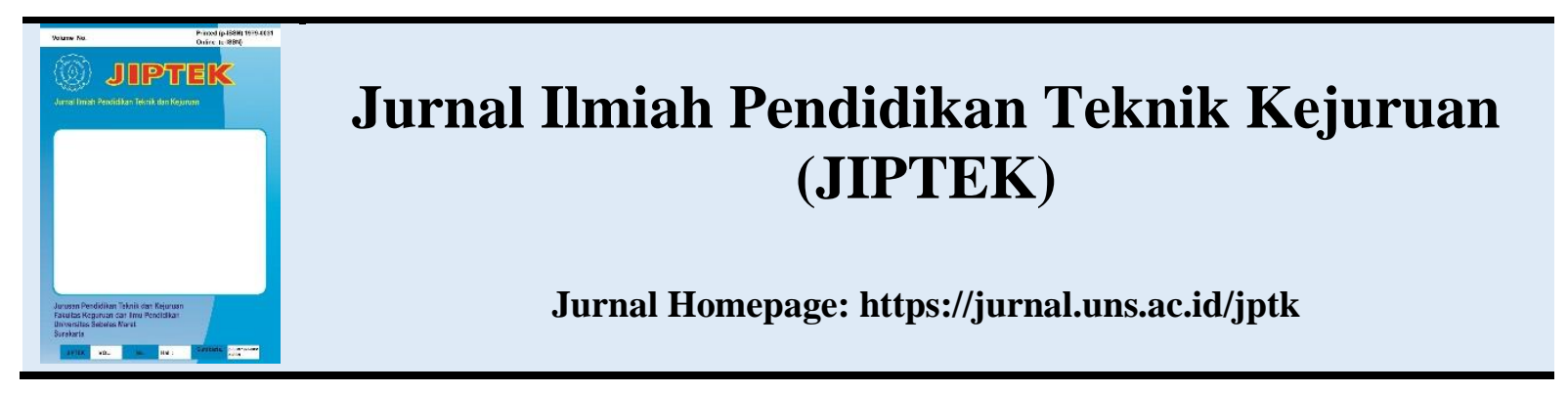

\title{
STUDI EKSPERIMENTAL PENGARUH PENAMBAHAN BAMBU PETUNG SEBAGAI FIBER TERHADAP KUAT LEKAT BETON SERAT PASCA BAKAR
}

\author{
Aryanti Nurhidayati ${ }^{1}$, Anis Rahmawati ${ }^{2}$, Ida Nugroho Saputro ${ }^{3}$, Eko Rosdianto ${ }^{4}$ \\ 1,2,3,4 Program Studi Pendidikan Teknik Bangunan, Universitas Sebelas Maret \\ E-mail: aryantinur79@gmail.com
}

\begin{abstract}
Abstrak
Tujuan dari penelitian ini untuk (1) mengetahui pengaruh penambahan variasi panjang serat bambu terhadap kuat lekat beton pasca bakar; (2) mengetahui ukuran serat bambu dan suhu pembakaran optimal yang menghasilkan kuat lekat maksimal pada beton serat pasca bakar. Penelitian menggunakan metode kuantitatif eksperimen dan teknik analisa data secara deskriptif. Variabel yang mempengaruhi dalam penelitian ini adalah (1) Variabel bebas : (a) variasi penambahan serat bambu yaitu $20 \mathrm{x} 1 \mathrm{x}$ $1 \mathrm{~mm}, 30 \times 1 \times 1 \mathrm{~mm}$, dan $40 \times 1 \times 1 \mathrm{~mm}$, (b) variasi suhu pembakaran yaitu $200^{\circ} \mathrm{C}, 300^{\circ} \mathrm{C}$, dan $400^{\circ} \mathrm{C}$ (2) Variabel terikat : kuat lekat beton serat pasca bakar akibat penambahan variasi serat bambu. Benda uji penelitian ini adalah silinder sebanyak 64 buah dengan ukuran diameter $15 \mathrm{~cm}$ dan tinggi $30 \mathrm{~cm}$ yang ditengahnya diberi baja tulangan berdiameter $12 \mathrm{~mm}$, untuk menguji kuat lekat beton serat bambu pasca bakar. Hasil penelitian sebagai berikut, (1) Adanya penambahan serat bambu berpengaruh kuat terhadap pada kuat lekat beton pasca bakar. (2) Penambahan serat bambu pada beton dengan panjang 3 $\mathrm{cm}$ yang dibakar pada suhu $200^{\circ} \mathrm{C}$ menghasilkan nilai kuat lekat tertinggi, yaitu $42,047 \mathrm{~kg} / \mathrm{cm}^{2}$.
\end{abstract}

Kata Kunci: inovasi, serat, temperatur.

\begin{abstract}
The purpose of this study is to (1) find variations in the length of bamboo fiber against the firm adhesion of post-burn concrete; (2) Study the size of bamboo fiber and the optimal temperature that produces maximum adhesion to post-burn fiber concrete. The research uses quantitative research methods and descriptive data analysis techniques. The variables that influence this study are (1) Independent variables: (a) variations in bamboo fiber namely $20 \times 1 \times 1 \mathrm{~mm}, 30 \times 1 \times 1 \mathrm{~mm}$, and $40 \times 1 \times 1 \mathrm{~mm}$, (b), and $400 \circ \mathrm{C}$ (2) Variables accepted: fiber concrete adherence of fiber The test material of this study was 64 tubes with a diameter of $15 \mathrm{~cm}$ and a height of $30 \mathrm{~cm}$ in the middle of which were given $12 \mathrm{~mm}$ diameter steel reinforcement, to strengthen the adhesive strength of post-burn bamboo fiber concrete. The results of the study are as follows, (1) The presence of bamboo fibers strongly supports the strong adhesion of post-burn concrete. (2) The addition of bamboo fiber to a $3 \mathrm{~cm}$ long concrete which was burned at a temperature of $200^{\circ} \mathrm{C}$ resulted in the highest adhesive strength value, namely $42,047 \mathrm{~kg} /$ $\mathrm{cm}^{2}$.
\end{abstract}

Keywords: innovation, fiber, temperature.

\section{PENDAHULUAN}

Kemajuan di bidang IPTEK sangat berpengaruh besar dalam segala bidang, terutama bidang konstruksi dan perbaikan beton. Hal ini menyebabkan mulai banyaknya inovasi - inovasi terhadap beton melalui 
pengembangan dan penyempurnaan kualitas dan mutu beton, salah satunya dengan penambahan serat pada beton. Maksud utama penambahan serat dalam beton adalah untuk menambah kuat tarik beton, mengingat kuat tarik beton sangat rendah. Kuat tarik yang sangat rendah berakibat beton sangat mudah retak, yang pada akhirnya mengurangi keawetan beton. Dengan adanya serat, diharapkan beton menjadi lebih tahan retak.

Jenis serat yang biasanya dalam beton dapat berupa serat baja, serat plastik, maupun serat alami. Namun pada penelitian ini penambahan serat pada beton menggunakan serat bambu. Serat bambu dipilih karena memiliki beberapa keunggulan, yaitu serat bambu dapat diperbarui dan mudah untuk dijumpai. Selain itu bambu memiliki kuat tarik yang tinggi sehingga dapat meningkatkan kekuatan beton. Penelitian sebelumnya tentang serat bambu dilakukan oleh Mudji $(1999,88-$ 90) bahwa mencampurkan serat bambu legi pada beton dengan variasi $0 \%, 1,5 \%$ dan $3 \%$ dari berat semen dapat mempengaruhi kekuatan beton. Kenaikan terbesar terjadi pada variasi $1,5 \%$.

Salah satu persyaratan dalam struktur beton bertulang adalah adanya lekatan antara tulangan dengan beton sehingga apabila pada struktur beton tersebut diberikan beban tidak akan terjadi selip antara tulangan dan beton, asalkan tersedia panjang penyaluran (development length) yang cukup. Hilangnya lekatan antara beton dengan tulangan pada struktur mengakibatkan keruntuhan total pada balok. Untuk menghindari hal tersebut perlu ditinjau nilai kuat lekat beton dan nilai kuat leleh tulangan agar diperoleh keseimbangan gaya antara tulangan dan beton. Keseimbangan yang dimaksud adalah gaya-gaya yang mampu ditahan oleh lekatan antara tulangan dan beton sama dengan gaya yang mampu ditahan oleh tulangan pada batas leleh.

Terjadinya perubahan temperatur yang cukup tinggi, seperti yang terjadi pada peristiwa kebakaran, akan berpengaruh terhadap elemen-elemen struktur. Karena pada proses tersebut akan terjadi suatu siklus pemanasan dan pendinginan yang bergantian, yang akan menyebabkan adanya perubahan fase fisis dan kimiawi secara kompleks, hal ini akan mempengaruhi kualitas/kekuatan struktur beton tersebut dan akan menyebabkan beton menjadi getas (Wahyuni, E. dan Anggraini, R., 2010). Masalah utama yang dihadapi dalam menangani bangunan pasca kebakaran adalah bagaimana menaksir kekuatan sisa bangunan pasca kebakaran. Dengan diketahuinya kekuatan sisa, kita dapat melakukan tindakan perbaikan yang paling efisien untuk memulihkan kondisinya seperti semula. Sehingga bangunan yang telah mengalami kebakaran dapat difungsikan kembali. Selama ini, bangunan yang telah mengalami kebakaran langsung dibongkar/dihancurkan (demolished action), padahal mungkin elemen struktur bangunan yang terbakar tersebut masih memiliki kekuatan (Wahyuni, E. dan Anggraini, R., 2010).

Berdasarkan uraian di atas dilakukanlah penelitian untuk mengetahui hubungan antara penambahan serat dan suhu pembakaran pada beton terhadap kuat lekat beton. Diharapkan dengan penambahan serat bambu pada beton 
diperoleh beton serat dengan kuat lekat tinggi sebelum dan sesudah kebakaran.

\section{METODE PENELITIAN}

\section{Waktu dan Tempat Penelitian}

Penelitian dilaksanakan dalam kurun waktu November 2017 sampai dengan Oktober 2018. Adapun tempat penelitian dipilih berdasarkan ketersediaan alat yang menunjang untuk dilakukan pengujian. Rincian tempat yang digunakan untuk pengujian adalah sebagai berikut :

1. Pengujian agregat halus dan kasar dilakukan di laboratorium PTB FKIP Universitas Sebelas Maret Surakarta

2. Pembuatan benda uji dilaksanakan di Laboratorium PTB FKIP Universitas Sebelas Maret

3. Pembakaran benda uji dilaksanakan di Sanggar Lebah, Ds. Pagerjurang, Bayat, Klaten, Jawa Tengah

4. Pengujian kuat lekat dilakukan di Laboratorium Teknik Sipil Universitas Sebelas Maret Surakarta

\section{Bahan}

Semen portland yang digunakan adalah semen tipe I yang diproduksi oleh PT. Semen Gresik yang merupakan anak perusahaan dari
PT. Semen Indonesia. Penggunaan semen ini sudah sesuai dengan standar Indonesia yang tercantum dalam SNI 7064-2004. Agregat kasar yang digunakan adalah agregat kasar dengan ukuran maksimal $20 \mathrm{~mm}$, diambil dari PT. Panca Beton Readymix yang beralamatkan di Bakalan, Ngasem, Colomadu, Kabupaten Karanganyar, Jawa Tengah. Untuk hasil pengujian agregat kasar dapat dilihat pada Tabel 1. Agregat halus diambil dari tambang pasir Gunung Merapi yang dipilih menggunakan pengayakan dengan ukuran saringan $0,5 \mathrm{~cm}$ dan memenuhi persyaratan uji gradasi. Untuk hasil pengujian agregat halus dapat dilihat pada Tabel 2 dan hasil pengujian gradasi dapat dilihat pada Gambar 1. Serat bambu yang digunakan adalah serat dari jenis bambu petung (Dendrocalamus Asper) yang diambil dari Ngaroyoso, Karanganyar, Jawa Tengah. Penambahan serat bambu pada beton sebanyak $1,5 \%$ dari berat semen dan ukuran serat bambu yang digunakan adalah $20 \mathrm{x} 1 \mathrm{x}$ $1 \mathrm{~mm}, 30 \mathrm{x} 1 \mathrm{x} 1 \mathrm{~mm}$, dan $40 \mathrm{x} 1 \mathrm{x} 1 \mathrm{~mm}$. Tulangan baja yang dipakai adalah tulangan baja polos dengan diameter $\pm 12 \mathrm{~mm}$.

Tabel 1. Sifat Fisik Agregat Kasar

\begin{tabular}{lllll}
\hline Parameter & Nilai & Standar & Keterangan & SNI \\
\hline $\begin{array}{l}\text { Bulk Specific } \\
\text { Gravity SSD }\end{array}$ & 2,6 & $2,5-2,7$ & $\begin{array}{c}\text { Memenuhi } \\
\text { Persyaratan }\end{array}$ & SNI 03-1970-1990 \\
\hline Abrasi & $46,47 \%$ & Min 40\% & $\begin{array}{c}\text { Memenuhi } \\
\text { Persyaratan }\end{array}$ & SNI 03-2417-1990 \\
\hline $\begin{array}{l}\text { Modulus } \\
\text { Kehalusan }\end{array}$ & 4,57 & $6-7,1$ & Butiran Kasar & SK SNI S-04-1989 F \\
\hline
\end{tabular}


Tabel 2. Sifat Fisik Agregat Halus

\begin{tabular}{lllll}
\hline Uji Bahan & Nilai & Standar & \multicolumn{1}{c}{ Keterangan } & SNI \\
\hline Kadar air & $0,20 \%$ & $1-3 \%$ & $\begin{array}{l}\text { Pasir dalam } \\
\text { keadaan terlalu } \\
\text { kering }\end{array}$ & \\
\hline $\begin{array}{l}\text { Kadar zat } \\
\text { organik }\end{array}$ & $0 \%$ & - & $\begin{array}{l}\text { Memenuhi } \\
\text { persyaratan, visual }\end{array}$ & - \\
\hline Kadar lumpur & $0,6 \%$ & $<5 \%$ & $\begin{array}{l}\text { Memenuhi } \\
\text { persyaratan }\end{array}$ & SK SNI S-04-1989 F \\
\hline $\begin{array}{l}\text { Bulk specific } \\
\text { gravity SSD }\end{array}$ & 2,52 & $2,5-2,7$ & $\begin{array}{l}\text { Termasuk agregat } \\
\text { normal }\end{array}$ & SNI 03-1970-1990 \\
\hline $\begin{array}{l}\text { Absorbsi } \\
\text { Modulus }\end{array}$ & $1,09 \%$ & Max 5\% & $\begin{array}{l}\text { Memenuhi } \\
\text { persyaratan }\end{array}$ & SNI 03-1970-1990 \\
\hline kehalusan & 2,48 & $1,5-3,8$ & $\begin{array}{l}\text { Memenuhi } \\
\text { persyaratan }\end{array}$ & SK SNI S-04-1989 F \\
\hline Gradasi & Daerah II & & Dapat digunakan & \\
\hline
\end{tabular}

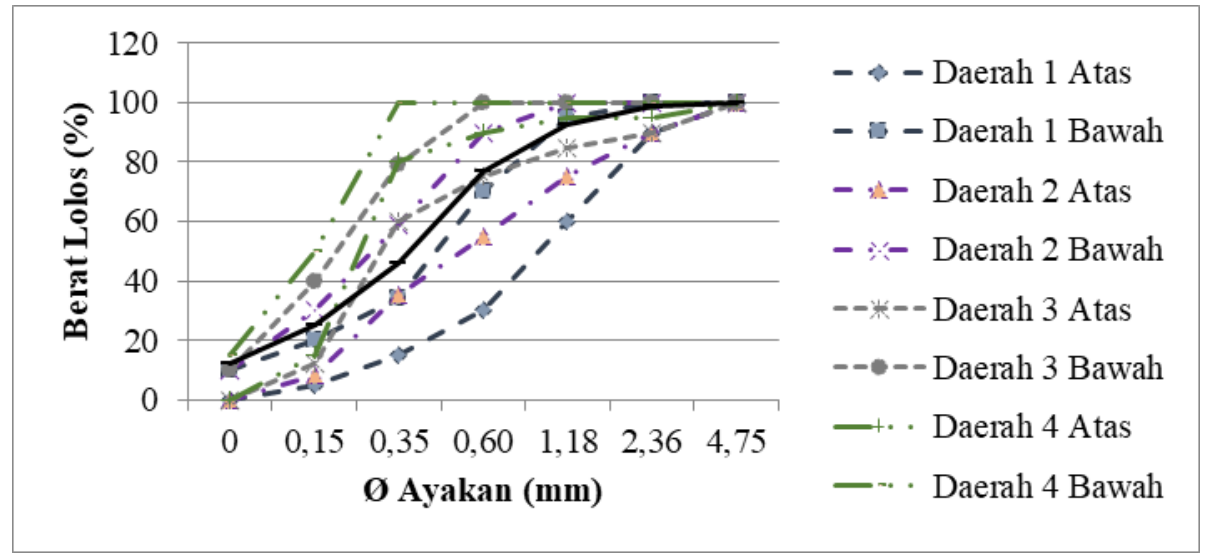

Gambar 1. Hasil Uji Gradasi Agregat Halus

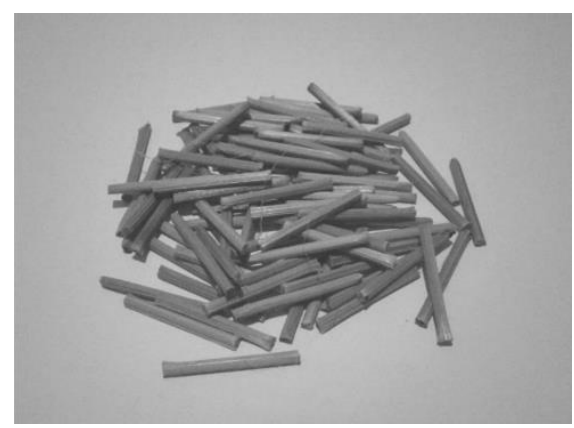

Gambar 2. Serat Bambu

\section{Perhitungan Rencana Adukan}

Perhitungan rencana adukan dilakukan untuk menentukan proporsi kebutuhan bahan campuran beton. Perhitungan rencana adukan pada penelitian ini menggunakan metode mix design sesuai dengan SNI 7656:2012. Hasil perhitungan rencana bahan adukan secara umum dapat dilihat pada Tabel 3. 
Tabel 3. Rekapitulasi Perhitungan Rencana Adukan

\begin{tabular}{lllllll}
\hline \multirow{2}{*}{ Variasi } & \multirow{2}{*}{ Volume } & \multicolumn{2}{l}{ Kebutuhan Bahan } & & \\
\cline { 3 - 7 } & & Semen $(\mathbf{k g})$ & Pasir $(\mathbf{k g})$ & Kerikil $(\mathbf{k g})$ & Bambu $(\mathbf{g r})$ & Air $(\mathbf{L t})$ \\
\hline & $1 \mathrm{~m}^{3}$ & 297,10 & 868 & 984,64 & 0 & 213,88 \\
\hline $0 \%$ & 1 Silinder & 2,047 & 5,979 & 6,783 & 0 & 1,473 \\
\hline $1,5 \%$ & 1 Silinder & 2,047 & 5,979 & 6,783 & 30,698 & 1,473 \\
\hline
\end{tabular}

\section{Pembuatan Benda Uji}

Untuk pengujian kuat lekat, benda uji berupa silinder beton dengan diameter $150 \mathrm{~mm}$ dan tinggi $300 \mathrm{~mm}$ sebanyak 64 buah. Pertama - tama siapkan cetakan molding baja dan bersihkan. Cetakan yang telah dibersihkan kemudian dilumasi dengan minyak agar beton tidak menempel pada cetakan. Selanjutnya agregat halus, semen, agregat kasar, dan serat bambu dicampur dalam keadaan kering di dalam mixer selama +3 menit. Setelah itu air ditambahkan ke campuran dan tunggu sampai campuran benar - benar homogen. Campuran beton segar dimasukan kedalam cetakan dengan menggunakan sendok semen dan dipadatkan menggunakan tongkat dan pengggetar sampai permukaan adukan beton terlihat basah dan tidak ada gelembung udara yang naik kepermukaan, kemudian diratakan. Menancapkan baja tulangan polos dengan diameter $12 \mathrm{~mm}$ sedalam $150 \mathrm{~mm}$ dari permukaan beton segar, dan memberi tanda (nomor) pada setiap cetakan. Setelah beton berumur 24 jam, cetakan dilepas, baja tulangan di cat minyak, dan beton direndam dalam air selama 28 hari.

\section{Pembakaran Benda Uji}

Setelah benda uji direndam selama 28 hari, tahap selanjutnya adalah pembakaran terhadap beton serat yang telah melalui proses perendaman. Suhu pembakaran beton adalah $200{ }^{\circ} \mathrm{C}, 300{ }^{\circ} \mathrm{C}$, dan $400{ }^{\circ} \mathrm{C}$ selama 1 jam. Pembakaran benda uji dilakukan di Sanggar Lebah, Ds. Pagerjurang, Bayat, Klaten, Jawa Tengah. Proses pembakaran dilaksanakan dengan cara sebagai berikut :

1. Siapkan tabung gas elpigi dan korek api

2. Cek burner sebelum dinyalakan dan disambungkan dengan gas elpigi

3. Masukkan benda uji ke dalam tungku pembakaran yang telah dilapisi glass wol dengan diletakkan secara vertikal

4. Tutup benda uji dengan plat tipis dan bagian luar dilapisi 2 lembar glass wol agar suhu dalam tungku tetap terjaga (stabil)

5. Nyalakan burner menggunakan korek api dana tur besar kecilnya gas agar mencapai suhu yang telah ditetapkan

6. Pemanasan untuk mencapai suhu dilakukan selama 15 - 30 menit menyesuaikan besar kecilnya suhu yang telah ditetapkan, kemudian suhu ditahan selama 1 jam

7. Setelah 1 jam, pendinginan dilakukan selama kurang lebih 1 jam dengan keadaan plat tipis dan glass wol bagian luar terbuka

8. Benda uji dikeluarkan dari tungku dan diletakkan di tempat yang aman. 


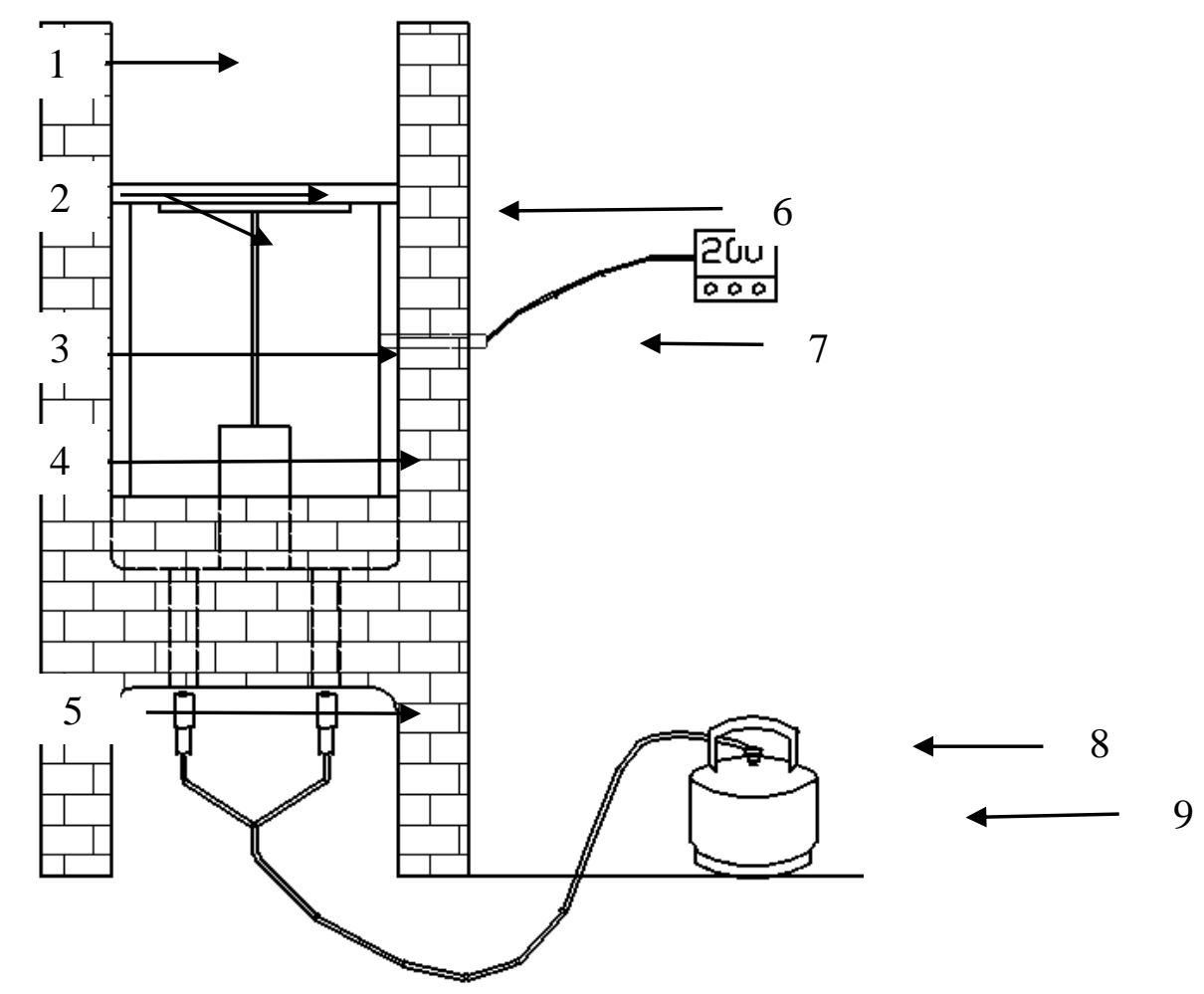

Gambar 3. Skema Pembakaran Beton

Keterangan :

1. Batu bata tahan panas (tungku)

2. Glass wol

3. Baja tulangan diameter $12 \mathrm{~mm}$

4. Silinder kuat lekat diameter $150 \mathrm{~mm}$ dengan tinggi $300 \mathrm{~mm}$

5. Burner

6. Pelat tipis penahan panas

7. Thermocouple

8. Regulator

9. Tabung Gas

\section{Pengujian Kuat Lekat}

Pengujian kuat lekat (Pull out) dilakukan setelah benda uji beton mencapai umur 28 hari menggunakan alat Universal Testing Machine (UTM) sesuai ketentuan SNI 03-4809-1998. Hal ini bertujuan untuk mengetahui apakah penambahan serat bambu dan suhu pembakaran pada beton yang diuji berpengaruh signifikan terhadap kuat lekat beton serat pasca bakar.

\section{Hasil Pengujian Kuat Lekat}

Nilai kuat lekat merupakan rata-rata hasil dari nilai kuat lekat tiga benda uji. Hasil menunjukkan bahwa beton dengan penambahan serat bambu panjang $3 \mathrm{~cm}$ memiliki kuat lekat tertinggi daripada beton lainnya. Untuk lebih jelasnya bisa dilihat pada Gambar 4. 


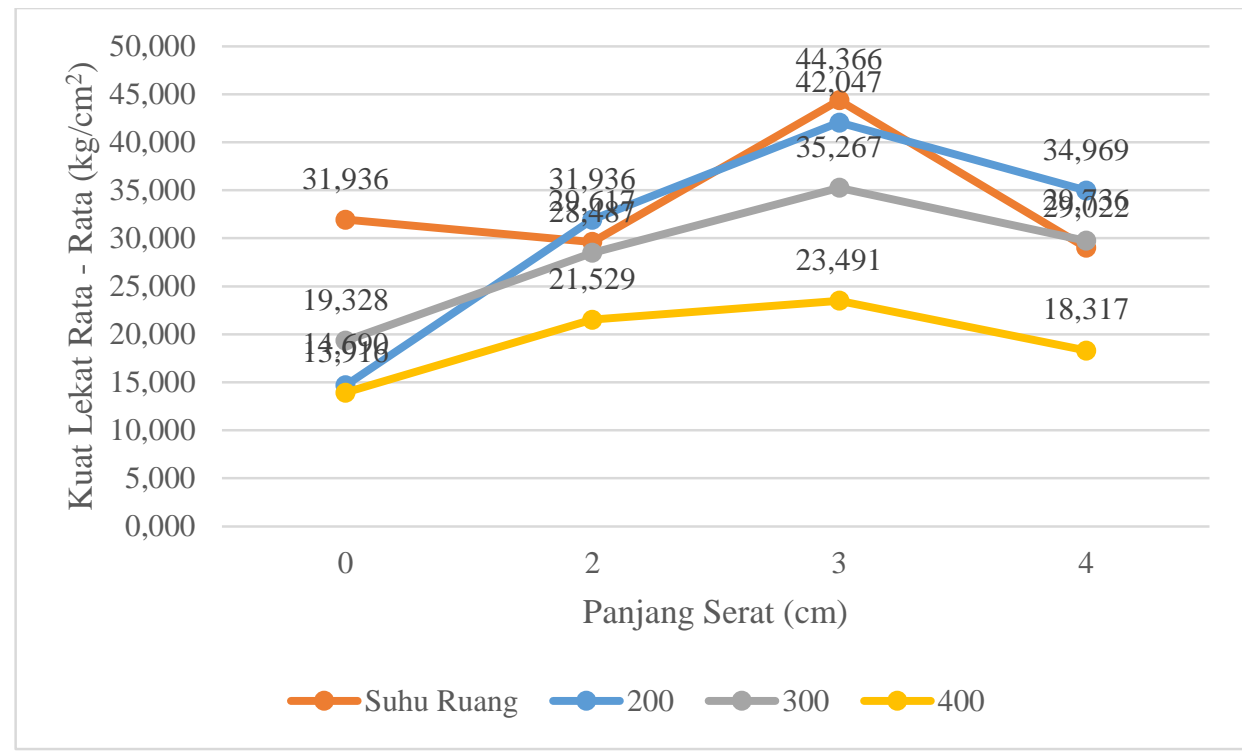

Gambar 4. Grafik Hubungan Variasi Ukuran Panjang Serat Bambu dan Kuat Lekat Terhadap Variasi Suhu Pembakaran

\section{PEMBAHASAN}

Berdasarkan grafik pada Gambar 4, ukuran panjang serat bambu dan suhu pembakaran optimal yang menghasilkan kuat lekat maksimal adalah beton dengan penambahan serat $3 \mathrm{~cm}$ dengan suhu pembakaran $200^{\circ} \mathrm{C}$, yaitu sebesar 42,047 $\mathrm{kg} / \mathrm{cm}^{2}$. Untuk semua beton serat yang dibakar pada suhu $200^{\circ} \mathrm{C}$ semuanya mengalami peningkatan kuat lekat jika dibandingkan dengan beton serat lainnya yang dibakar pada suhu $300^{\circ} \mathrm{C}$ dan $400^{\circ} \mathrm{C}$, penyebabnya adalah beton dengan penambahan serat $2 \mathrm{~cm}$ yang dibakar pada suhu $200^{\circ} \mathrm{C}$ selama 1 jam tersebut mengalami titik kering maksimal sehingga kuat lekat beton meningkat, dan setelah suhu dinaikkan penurunan kuat lekat beton terjadi akibat beton telah melalui titik kering maksimal. Hal ini sesuai dengan penelitian (Atmajaya, F.R., 2016) yang menyatakan bahwa beton yang mengalami pasca kebakaran rata-rata kuat tekannya menurun, namun diasat didurasi pembakaran selama 6 jam beton mengalami peningkatan kuat tekan di karenakan beton tersebut mencapai titik kering maksimal dan setelah 6 jam terbakar beton tersebut mengalami penurunanan kuat tekan kembali dikarenakan beton telah melewati titik maksimal kekuatan terbakarnya sehingga beton tersebut mengalami penurunan kuat tekan. Namun titik kering maksimal beton disini bergantung pada besarnya suhu pembakaran dan durasi pembakaran.

Berdasarkan grafik pada Gambar 4, beton dengan penambahan serat $2 \mathrm{~cm}, 3 \mathrm{~cm}$, maupun $4 \mathrm{~cm}$ memiliki kuat lekat yang lebih besar dibanding beton normal, dengan ukuran serat $3 \mathrm{~cm}$ sebagai ukuran optimal penambahan serat bambu yang menghasilkan kuat lekat maksimal beton. Penyebab peningkatan kekuatan tersebut adalah kecenderungan serat bambu untuk menyerap dan menyimpan air, sehingga dengan penambahan serat bambu dalam campuran beton, ketika terjadi kebakaran air yang menguap dari campuran beton dapat digantikan dengan air yang terkandung dalam serat bambu, akibatnya keretakan yang timbul 
akibat pembakaran dapat dicegah. Hal ini sejalan dengan (Sari D.W., 2013) dalam penelitiannya menyatakan ketika beton normal mengalami kebakaran maka air yang ada di dalam beton akan membentuk lorong-lorong kecil dan pada akhirnya akan menguap menimbulkan keretakan yang menyebabkan kekuatan beton menurun. Sehingga dengan penambahan ban karet dalam campuran beton, ketika terjadi kebakaran dapat menggantikan air yang hilang dan kemudian mencegah keretakan yang timbul akibat kekeringan. Hal ini berarti penambahan serat bambu berdampak positif meningkatkan kuat lekat beton baik tanpa pembakaran maupun melalui proses pembakaran.

\section{KESIMPULAN}

Dari hasil penelitian dan pembahasan tentang studi eksperimental pengaruh penambahan bambu petung sebagai fiber terhadap kuat lekat beton serat pasca bakar dapat ditarik kesimpulan sebagai berikut:

1. Ada pengaruh yang bersifat positif pada variasi ukuran panjang serat bambu terhadap kuat lekat beton pasca bakar.

2. Terdapat nilai optimal ukuran panjang serat bambu dan suhu pembakaran terhadap kuat lekat maksimal beton yang dihasilkan yaitu kuat lekat berada pada ukuran panjang serat bambu 30 $\mathrm{mm}$ dan suhu $200^{\circ} \mathrm{C}$ dengan kuat lekat maksimal sebesar $42,047 \mathrm{~kg} / \mathrm{cm}^{2}$.

SARAN
1. Perlu adanya penelitian lebih lanjut tentang perubahan senyawa kimia yang terjadi pada beton pasca bakar dengan bahan tambah serat bambu.

2. Perlu adanya penelitian lebih lanjut tentang penambahan admixture (bahan tambah) pada beton pasca bakar dengan menggunakan serat bambu sehingga dihasilkan kuat lekat yang baik.

3. Perlu adanya penelitian lebih lanjut tentang kuat lekat beton serat bambu pasca bakar yang menggunakan tulangan ulir.

4. Perlu adanya penelitian lebih lanjut tentang proses pembakaran beton dengan suhu yang lebih tinggi.

\section{DAFTAR PUSTAKA}

(1989). Standar Nasional Indonesia S04-1989-F. Spesifikasi Bahan Bangunan Bagian A, Bahan Bangunan Bukan Logam. Badan Standardisasi Nasional.

.(1990). Standar Nasional Indonesia 031970-1990. Metode Pengujian Berat Jenis Dan Penyerapan. Air Agregat Halus. Badan Standarisasi Nasional. .(1991). Standar Nasional Indonesia 032417-1991. Metode Pengujian Keausan Agregat Dengan Mesin Abrasi Los Angeles. Badan Standarisasi Nasional.

(1998). Standar Nasional Indonesia 03-4809-1998. Metode Pengujian Untuk Membandingkan Berbagai Beton Berdasarkan Kuat Lekat Yang Timbul Terhadap Lingkungan. Badan Standarisasi Nasional.

.(2004). Standar Nasional Indonesia 15-7064-2004. Semen Portland Komposit. Badan Standardisasi Nasional.

.(2012). Standar Nasional Indonesia 7656:2012. Tata cara pemilihan 
campuran untuk beton normal, beton berat dan beton massa. Badan Standarisasi Nasional.

Atmajaya, F.R. (2016). Struktur Beton Pasca Kebakaran Terhadap Kuat Tekan Dan Karakteristik Beton. Jurnal Penelitian. Universitas Serang Raya. Diperoleh pada 2 Oktober 2018.

Asroni , Ali. (2010). Balok dan Pelat Beton Bertulang. Yogyakarta : Graha Ilmu.

Morisco. (1996). Bambu sebagai Bahan Rekayasa. Pidato Pengukuhan Jabatan Lektor Kepala Madya Fakultas Teknik UGM. Yogyakarta.

Mulyono, Tri. (2005). Teknologi Beton. Yogyakarta : Naviri Offset.

Pedoman Penulisan Skripsi. (2016). Surakarta : FKIP Universitas Sebelas Maret.

Sari D.W. (2013). Kinerja Beton Berserat Karet Pada Suhu Tinggi. Jurnal Penelitian. Universitas Riau. Diperoleh pada 2 Oktober 2018.
Sugiyono. (2010). Statistika Untuk Penelitian. Bandung: Alfabeta.

Suhardiman, Mudji. (2015). Kajian Pengaruh Penambahan Serat Bambu Ori Terhadap Kuat Tekan Dan Kuat Tarik Beton. Jurnal Penelitian. Universitas Janabadra. Diperoleh pada 25 April 2018.

Tjokrodimuljo, K.I., (2000). Teknologi Beton. Yogyakarta: Biro Penerbit.

Wahyuni, E., Anggraini, R. (2010). Pengaruh Perbedaan Proses Pendinginan Terhadap Perubahan Fisik Dan Kuat Tekan Beton Pasca Bakar. Jurnal Rekayasa Sipil / Volume 4, No.1-2010 ISSN 1978 - 5658. Diperoleh pada 19 September 2018. 